\title{
@SAGE researchmethods cases \\ Using Ethnographic Discourse Analysis to Understand Doctor-Patient Interactions in Clinical Settings
}

Contributors: Jack Pun, Christian M. I. M. Matthiessen, Geoff Williams \& Diana Slade Pub. Date: 2016

Access Date: February 12, 2017

Academic Level: Intermediate Undergraduate

Publishing Company: SAGE Publications Ltd

City: London

Online ISBN: 9781473979697

DOI: http://dx.doi.org/10.4135/9781473979697

(C2017 SAGE Publications Ltd. All Rights Reserved.

This PDF has been generated from SAGE Research Methods Cases. 


\begin{abstract}
Using ethnographic discourse analysis in an Emergency Department in Hong Kong, this study explored the features of doctor-patient interactions in a hospital setting. By audio-recording 10 patient journeys, from triage to disposition, we analyzed the complexity of turn-taking patterns in spoken interactions between patients and doctors, as well as the subsequent complexities in this communication process. In particular, we traced the flow of communication surrounding the patients' medical conditions at different stages of their journeys (e.g., taking patient history, making diagnosis and translating medical information in a bilingual environment). Communication in this Emergency Department, as in all Emergency Departments in Hong Kong, involves repeated translation from spoken Cantonese interactions to the written English patient notes and vice versa. For this study, the ethnographic discourse analysis includes different layers of detailed language diagnoses of the observed interactions (e.g., turn-taking strategies, speech functions and exchange structures). In this analysis, we examined the strategies that doctors used to transfer medical knowledge to their patients and with other clinicians; this research illustrated how a series of contextual factors (e.g., time pressure, staff shortages) were linked with the quality of doctor-patient communication. To illuminate the path for future research, we developed a dual-goal communication framework focusing on both medical and interpersonal aspects of the doctor-patient relationship. We strongly recommend the application of this framework for training medical students, junior clinicians and clinicians in practice.
\end{abstract}

\title{
Learning Outcomes
}

By the end of this case students should be able to

- Identify the discrete stages of a patient journey as a series of communicative events and highlight the key contextual features that contribute to the complexity of the journey

- Analyze the flow of information from spoken interactions, from healthcare professionals to patients and between healthcare professionals within a bilingual context; (this research focused on Hong Kong, which is a multicultural city with two official languages: Chinese and English)

- Identify the breakdowns in communication (i.e., misunderstandings) that occurred in these spoken interactions

- Explain how language and communication research can improve healthcare practitioners' understanding of communicative styles in culturally diverse societies

- Contribute to advances in applied linguistic research by developing a discourse analysis framework for healthcare interactions in high-stress contexts; the key communicative 
strategies in this framework help clinicians achieve effective communication in Emergency Departments (EDs)

\section{Project Overview and Context}

The goal of this research was to develop a deeper understanding of how clinicians and patients communicate in a high-risk clinical context. This research is particularly relevant to the issues of patient safety and satisfaction in Emergency Departments (EDs). By audio-recording 10 patient journeys, from triage to disposition, we analyzed the complexity of turn-taking patterns in spoken interactions between patients and doctors, as well as the subsequent complexities in this communication process. In addition, we administrated 58 questionnaire surveys to the ED staff and conducted semi-structured interviews with 28 doctors and nurses in order to understand their views of healthcare communication in an ED context. This research has led to several publications that reported the major findings on the language analysis of patient journeys, the results from the questionnaires and interviews with clinicians (Chandler et al., 2015; Rider et al., 2014; Slade et al., 2015; Slade, Matthiessen, Lock, Pun, \& Lam, 2016).

Initial consultations in EDs are complex social sites for the exchange of meanings. The process of exchange occurs primarily through language (notwithstanding the significant role of other modalities, particularly gesture). Since language is the key mode through which meaning is created and interpreted, the role of language in healthcare communication merits close research attention.

For this research study, the purpose of the speech function, exchange structure and move analysis was to focus on the micro-interaction of the doctor-patient consultations. The relationship between moves produced by different speakers was captured by speech function and exchange structure analysis. (This work involved categorizing each move according to its function in that context.) The speech function and exchange structure analyses focused on the interactivity of the conversations. The concern in these analyses was to demonstrate how the interaction between the clinicians and patients unfolds and the nature of each of the participant's contribution.

Semantic networks are linguistic maps of the meanings people typically make when they use language in context (Halliday, 1973; Hasan, 1983, 1996, 2009; Williams, 1995, 2001). Since meanings rely on wordings, and wordings make a critical difference to meanings, semantic networks use people's wordings to investigate the ways in which they "mean" through questions. One distinction between the wording and meaning of questions is very familiar: the distinction between "W" questions such as "What, Why ..." and questions to which "yes/no" is 
the expected response. A semantic network for studying questions extends this general distinction to look at much more specific options for asking questions through different wordings (e.g., "You didn't have this pain before, did you?" "You had this pain before, did you?" "Have you had this pain before?" "When have you had this pain before?'). A doctor who asks, "What were you doing when you first noticed this pain?" is likely to elicit different meanings from one who asks, "Why do you think this pain started?" The meanings of patients' responses to different types of questions also require careful investigation. Do some types of questions succeed in eliciting more relevant information than others? Do some questions cause patients to feel uncomfortable? Do some questions seem particularly difficult for patients to understand? Semantic networks provide valuable techniques for studying patients' responses, exploring response features such as compliance or refusal (which can be quite linguistically subtle), categorizing the relevance of responses, assessing the extent of response elaboration, and so on.

In summary, this study involved detailed linguistic analysis through the speech function, exchange structure and move analysis; the semantic networks generated by this work provided a finely detailed map of the exchange of meanings in this type of context. This map displayed the potential of meaning exchanges in an ED context, revealing which areas show the greatest risk for misunderstandings or omissions; these areas were tested against the analysis of actual data and accompanied by examples of real exchanges. The analysis was then represented in computational form, extending contemporary studies of discourse. This work may be used as a basis for professional development for clinicians, to enhance clinician-patient communication.

\section{Research Practicalities}

This project was carried out between August and October 2011 in the ED of a large public hospital in Hong Kong. The work was supported by internal grants from the Faculty of Humanities of Hong Kong Polytechnic University. The two ethics committees of the University and the participating hospital approved this study. Seven researchers, from a range of disciplines (e.g., linguistics, communication and emergency medicine) spent $80 \mathrm{hr}$ doing direct observation in the ED, audio-recording 10 patient journeys, conducting 28 interviews and administering 58 questionnaires to clinicians.

The audio-recorded observation of 10 patients, from triage to disposition, captured the essential elements, patterns and strategies in spoken interactions between doctors and patients. The questionnaire consisted of 15 multiple-choice items, asking the clinicians' views towards, and experiences of, clinician-patient and clinician-clinician communication. The interviews explored communication events in the ED, including verbal and written modes of communication 
between clinicians and patients, as well as between clinicians themselves.

The methodological challenges were as follows:

1.Access and response rate: Our study employs a cross-disciplinary approach. Our diverse research team worked with ED clinicians and the management of the hospital. We had collaborative discussions about the research design, data collection and analysis. Prior to data collection, we held briefing sessions with all participating staff; we explained the aims of the study and the participants' rights in the research project. We ensure their identities remained anonymous and by participating in this study their relationship with the hospital would not be affected. This is careful briefing about the research to healthcare professionals, hospital management and Hong Kong Hospital Authority officials. These detailed briefings are essential to ensure support and participation for our research. In the pilot study the briefings resulted in $100 \%$ response rate to the questionnaire by the ED staff, and $100 \%$ positive response to request for interviews.

2.Working with multiple language data: For the patient journey data, all verbal interactions between the patients and the clinicians were be recorded and transcribed in Chinese by researchers who are native speakers. The transcriptions were sent to a professional translation service to be translated into standard English. The translations from this service were checked by native Cantonese speakers in the research team. Researchers developed files for each patient's interactions throughout the ED journey; these files displayed each interactive turn in conversations in Cantonese, Romanized Cantonese script with tone descriptions (using a standard description of tone types), and in English translation. These procedures ensured that all data were intact, meticulously translated and presented in a standard master data set.

3. Hawthorne effect: We acknowledge that a Hawthorne could influence the research results. The Hawthorne effect derived from a study of the psychological aspects plus physical and environmental influences in the workplace and the results implied that participants in a research study may change their behaviors simply because of the attention they receive, regardless of any experimental manipulation (Sedwick, 2012). However, the data-gathering techniques for this study do not tend to produce a Hawthorne effect because of key features of the ED context. In particular, the highly dynamic and stressful nature of ED work means that the participants' focus will be on tasks rather than on the fact that they are observed during those tasks. In our previous research, participants who were in naturally occurring contexts have not, following an initial short adjustment, placed little attention on the recording process. Researchers believe this non-participating observation stems from the human need to sustain genuinely meaningful interactions in spoken language contexts. 
In addition, participants in this research project did not have concepts of "ideal" or "favored" features of the clinician-patient interactions, so systematic biasing would be unlikely. Lastly, our research assistants who observe patients' journeys know not to give any indication to participants about "favored" forms of interaction.

\section{Research Design}

This research study built upon and extended insights developed during a 3-year project describing clinician/patient communication in five EDs in Australia (Slade et al., 2011; Slade et al., 2015). This project involved $1093 \mathrm{hr}$ of observations, 150 interviews with key staff and patients and 82 recorded patient journeys. This research represented one of the most comprehensive studies on clinician-patient communication in the world. This research laid the groundwork for the methodological approach described in this study.

By using ethnographic discourse analysis for exploring meanings in clinician-patient interactions, this study sheds light on how clinician-patient relationships are established and built. Specifically the project will:

- Explore in detail the interpersonal dimension of the clinician/patient interactions, looking at the relationships between consecutive moves across different speakers

- Refine and utilize a semantic network to describe the different types of questions and responses used in ED consultations

- Explore how empathy and rapport are established with the patient, through a detailed analysis of the discourse strategies employed in the consultations

- Explain how applied discourse analysis can improve clinicians' understanding of effective relationships with patients in high-stress contexts

- Form the basis of a larger scale project that directly analyzes the bilingual data (English and Cantonese) for future research and program funding

This study developed and employed a communication framework for Cantonese doctor-patient interactions. This framework included different layers of analyses (e.g., speech function, exchange structure, move analysis, semantic network analysis ${ }^{1}$ and an analysis of the discourse strategies).

First, this research study developed previous work by Eggins and Slade (1997) on move analysis; the work explored both medical and interpersonal dimensions of the clinician-patient interactions by describing the interactional patterns across speaker turns. (This analysis documented the relationships that exist between consecutive moves across different speakers [e.g., patients and different clinicians]). Of particular interest was Eggins and Slade's 
description of different move types in spoken English, which were then adapted and applied to spoken Cantonese used in the healthcare consultations.

Clinicians' questions to patients are central to health services, especially in EDs, because these questions reveal a pattern of symptoms and lead to a diagnosis. For this study, researchers focused on the meanings of questions and responses to them, using the well-tested method of semantic network techniques (Halliday, 1973; Hasan, 1983, 1996, 2009; Williams, 1995, 2001). The research team refined and employed these semantic networks to describe the different question types and responses exchanged in the consultations.

Third, this research included an analysis of the discourse strategies clinicians use to develop rapport and empathy with patients. For example, researchers examined whether patients are given an opportunity to tell their story, to negotiate shared decision-making and share their knowledge and opinion.

In this research, by analyzing the interpersonal discourse strategies that clinicians use in spoken Cantonese, the research team described how clinician-patient relationships are established. Researchers then offer strategies to inform and improve healthcare practitioners' abilities to establish effective relationships with patients in high-stress contexts.

\section{Ethnographic Discourse Analysis in Action}

The data set consisted of audio-recordings of 10 patient journeys in the ED from triage to disposition. The research team used the transcribed clinician-patient consultation data as the foundation to develop the linguistics framework for analyzing natural responses in doctorpatient consultations. The researchers then developed a communication framework, involving two layers of analysis, for clinician-patient interactions in Cantonese. The two broad stages were as follows:

1.Researchers examined the speech function, exchange structure and move analysis that focused explicitly on the achievement of interactivity, where each move in the consultations involved a speech role and positioned the interactants into predicted speech roles. Researchers then looked at the sequencing of moves involved in the joint accomplishment of turn taking, exploring the unfolding of the interaction. (The move is defined as the basic analytical unit in interactive talk that selects for a speech function [Slade, 1997].) The steps in the move analysis involved the following:

i. The transcript was divided into moves. The analysis showed rhythm and intonation.

ii. The moves were labeled for speech function and speech function classes were assigned. The different speech function classes used in the analysis and the coding 
were based on Eggins and Slade (1997). Only the first move within the move complex was labeled for speech function as, by definition, the related moves realized the same speech function.

iii.The patterns of move choices were then related to the interpersonal context of the interaction. Through the register variable of tenor, patterns in interactivity can be related to contextual variables such as status relations, affective involvement and the contribution of the patient to the interaction.

The Cantonese data were translated into English for the move analysis while, for this research study, the salient features of interpersonal meanings in the original Cantonese data (such as the particles functioning as negotiators or attitudinal markers) were also captured in the analysis (in the form of phonetic transcription) to reflect how interpersonal meanings were actually manifested in the language. The validity of this analysis was tested against the original spoken Cantonese data by research team members who were native Cantonese speakers who were also well informed about Cantonese Linguistics.

\section{Example:}

In the following section, an example will be provided to show the coding is done using this linguistics framework for analyzing natural responses in doctor-patient consultations. We will demonstrate how we examined the speech functions and exchange structures through the move analysis that focused explicitly on the achievement of interactivity in doctor-patient consultation.

Each move in the exchanges was coded for the type of speech function it realizes. In Figure 1, we set out the moves in a typical exchange structure, which begins with initiating moves followed by responding moves that may either be supporting (e.g., acknowledgement) or confronting (e.g., contradiction). The speech function categorization of initiating and responding moves is based on Halliday and Matthiessen (2014). After the responding moves there may or may not be a third part to the exchange consisting of follow up moves. These moves typically complete the exchange, although there may also be feedback, which contributes only minimally to the exchange. 
Figure 1. Moves in Three-part (IRF) exchanges.

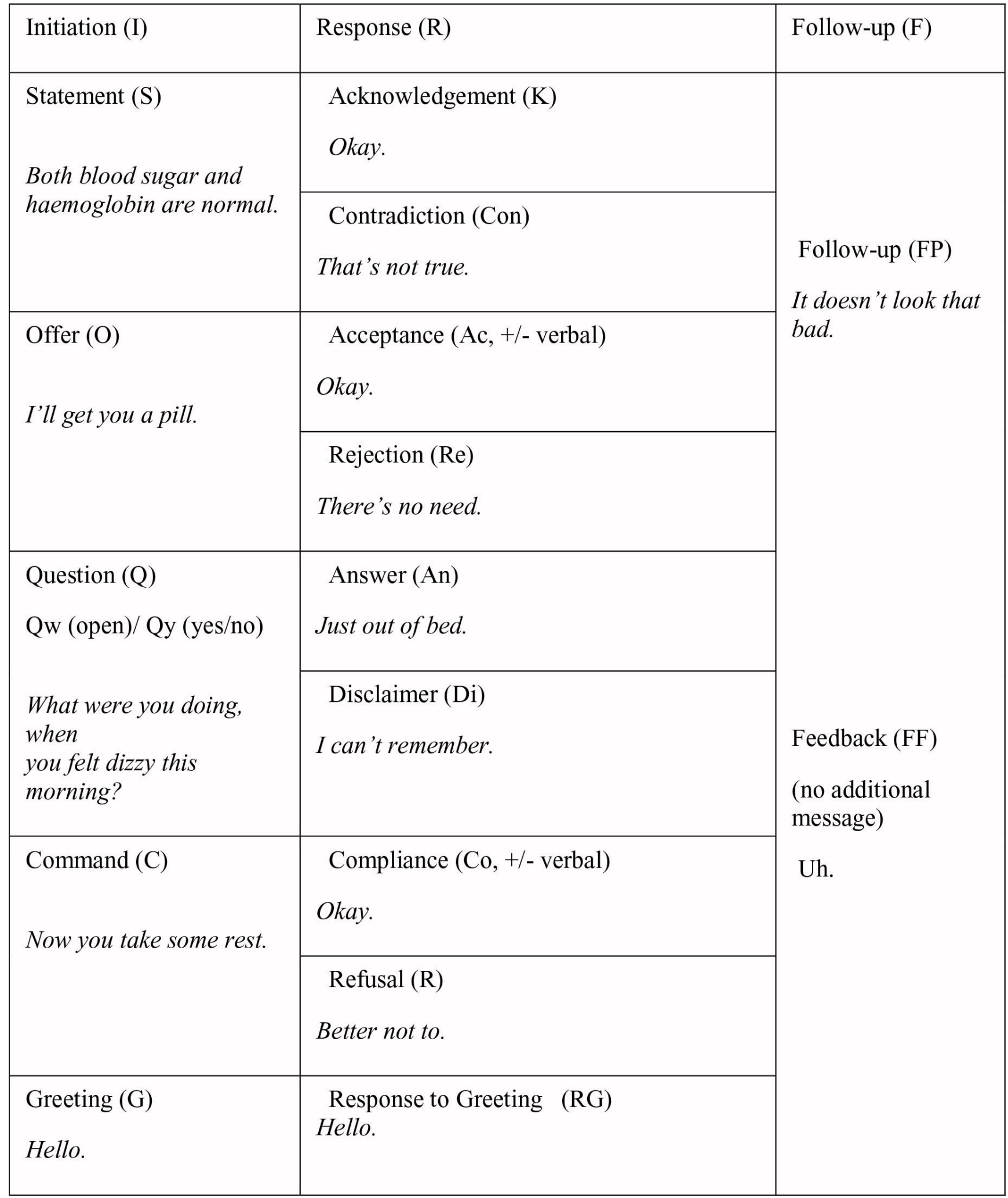

In Figure 2, we present the first few minutes of the consultation between Crystal and her doctor. We use this as an example to illustrate how the coding can be applied to analyze the natural responses in doctor-patient consultations in the transcripts. 
Figure 2. Crystal consultation at A\&E.

\begin{tabular}{|c|c|c|c|c|}
\hline Generic stages & Moves & Exchange & Speaker & Talk \\
\hline \multirow{3}{*}{$\begin{array}{l}\text { Establishing } \\
\text { identity and } \\
\text { greeting }\end{array}$} & 1. & Qy & $\mathrm{Dr}$ & Crystal, yes? \\
\hline & 2. & An & $\mathrm{P}$ & Ye-ye-ye-yes. \\
\hline & $3 a$ & G & $\mathrm{Dr}$ & Hello. \\
\hline \multirow{13}{*}{$\begin{array}{l}\text { Exploration of } \\
\text { condition }\end{array}$} & $8 \mathrm{c}$ & Qw & & What's the matter? \\
\hline & 9 & An & $\mathrm{P}$ & $\begin{array}{l}\text { Ah... I was dizzy when I got up at seven } \\
\text { o'clock this morning, like I was spinning and } \\
\text { such. }\end{array}$ \\
\hline & $10 \mathrm{a}$ & $\mathrm{Fp}$ & $\mathrm{Dr}$ & Mm, okay. \\
\hline & $10 \mathrm{~b}$ & Qy & & At seven o'clock you==woke up, right? \\
\hline & 11 & An & $P$ & $==$ Out - out of bed. \\
\hline & 12 & Qy & $\mathrm{Dr}$ & $==$ Did you pass out and such? \\
\hline & 13 & An & $P$ & $\begin{array}{l}\text { It... I mean, still awake, but when I walked, I } \\
\text { dipped and dipped. }\end{array}$ \\
\hline & 14 & Qy & $\mathrm{Dr}$ & Huh, did you vomit or something? \\
\hline & 15 & An & $\mathrm{P}$ & Ah, not yet. \\
\hline & $16 \mathrm{a}$ & Qy & $\mathrm{Dr}$ & You were still ambulatory? \\
\hline & $16 \mathrm{~b}$ & & & did you fall or something? \\
\hline & 17 & An & $P$ & I needed support. \\
\hline & $18 \mathrm{a}$ & FP & $\mathrm{Dr}$ & Uh. \\
\hline
\end{tabular}




\begin{tabular}{|l|l|l|l|l|}
\cline { 1 - 2 } & \multicolumn{1}{l|l|}{ Qy } & Did you hit your head? \\
\hline 19 & An & P & Ah... not that kind of thing. \\
\hline 20a & FP & Dr & nothing. \\
\hline
\end{tabular}

Description: $\mathrm{Dr}=$ Doctor; $\mathrm{P}=$ Patient $($ Crystal); $\mathrm{R}=$ Researcher .

Crystal is a female patient in her 40s. She lived alone in the New Territory of Hong Kong. On September 15, 2011, morning, she felt dizzy and had chest pain when she woke up in the morning. She felt terribly sick and she dialed 999 and call for help. She was then sent to the hospital A\&E by ambulance. Her triage category is semi-urgent. She was also a patient of panic disorder.

During the consultation, Crystal expressed her concern about being dizzy and would like to stay at the hospital for further check up. But her request was rejected by the doctor. During following up interview, Crystal expressed her disappointment about the A\&E doctor and nurses' unclear explanation, not addressing her request/feeling. One interesting point is that Crystal couldn't distinguish doctor from nurses, and she believed that the one who had medical consultation with her was a nurse.

This research also included an analysis of the discourse strategies clinicians use to develop rapport and empathy with patients. This analysis allowed researchers to understand (a) how doctors and nurses communicate with patients in exchanging medical knowledge and (b) how rapport and empathy are established. Table 1 is an example of the selected strategies for doctor to develop shared medical knowledge and decision-making with their patients.

Table 1. Selected strategies for developing shared medical knowledge and decisionmaking (adapted from Slade et al., 2015).

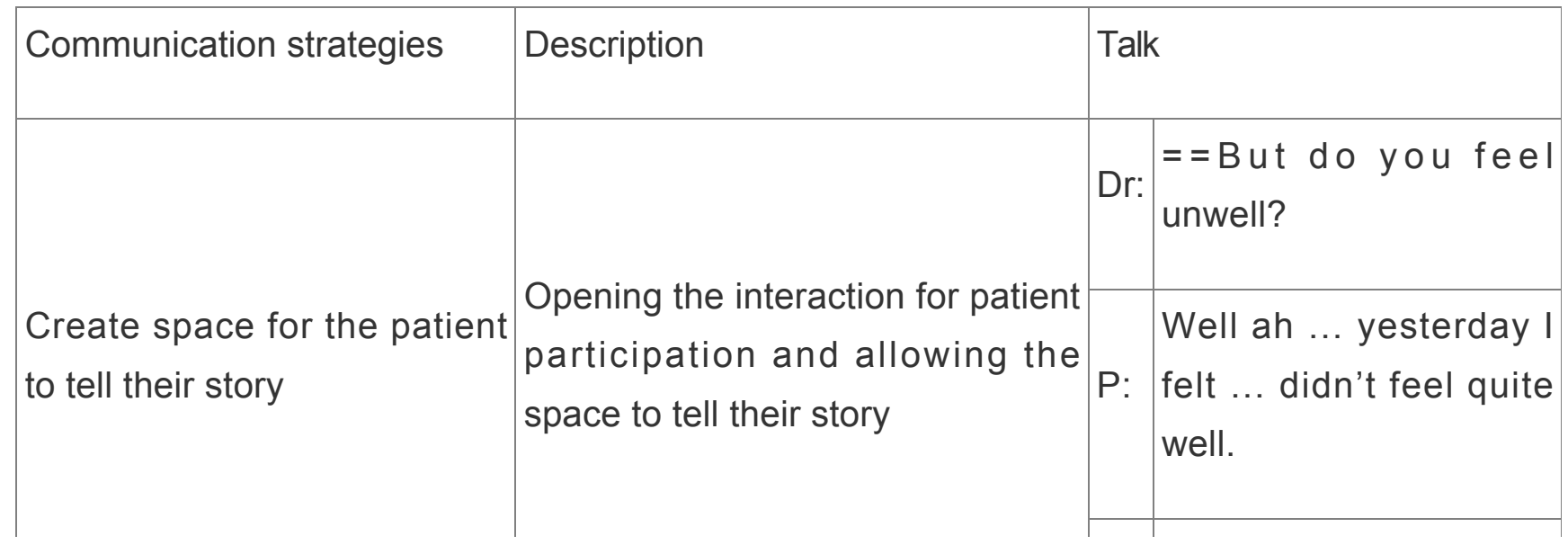


Dr: How so? Does it hurt?

\begin{tabular}{|c|c|c|c|}
\hline & & Dr: & How so? Does it hurt? \\
\hline \multirow{5}{*}{$\begin{array}{l}\text { Seek and recognize the } \\
\text { patient's knowledge and } \\
\text { opinions about their } \\
\text { condition. }\end{array}$} & $\begin{array}{l}\text { Facilitate the knowledge-building } \\
\text { process by eliciting and valuing } \\
\text { patients' knowledge about their } \\
\text { case and prior treatments. }\end{array}$ & Dr: & $\begin{array}{l}\text { But do you feel sore } \\
\text { today? You said you } \\
\text { started to f e e I } \\
\text { uncomfortable } \\
\text { yesterday, how about } \\
\text { today? Today. }\end{array}$ \\
\hline & \multirow{4}{*}{$\begin{array}{l}\text { Normalize patients' medical } \\
\text { symptoms and concerns about } \\
\text { what is happening to them. }\end{array}$} & $P:$ & $\begin{array}{l}\text { Here, I was leaning like } \\
\text { this. Perhaps the } \\
\text { pacemaker is here. }\end{array}$ \\
\hline & & Dr: & $\begin{array}{l}\text { That isn't a concern, the } \\
\text { metal is quite strong. If } \\
\text { nothing's loose, then } \\
\text { there's no problem. }\end{array}$ \\
\hline & & P: & $\begin{array}{l}\text { No, right? I don't know, I } \\
\text { got nervous, I, you } \\
\text { know how nervous I am. }\end{array}$ \\
\hline & & Dr: & $\begin{array}{l}\text { We II we did a n } \\
\text { electrocardiogram, } \\
\text { tested things out, } \\
\text { those-those signals are } \\
\text { very normal. }\end{array}$ \\
\hline \multirow{3}{*}{$\begin{array}{l}\text { Explain medical concepts } \\
\text { clearly by moving between } \\
\text { technical and common sense } \\
\text { language. }\end{array}$} & \multirow{3}{*}{$\begin{array}{l}\text { Limit technical language and } \\
\text { explain terms that patients might } \\
\text { not understand. }\end{array}$} & Dr: & $\begin{array}{l}\text { Signals from the } \\
\text { pacemaker are quite } \\
\text { good. }\end{array}$ \\
\hline & & P: & Right. \\
\hline & & Dr: & $\begin{array}{l}\text { Meaning that it hasn't } \\
\text { lost its functions, things } \\
\text { like that. }\end{array}$ \\
\hline
\end{tabular}




\begin{tabular}{|c|c|c|c|}
\hline \multirow{6}{*}{$\begin{array}{l}\text { Provide clear and easily } \\
\text { understandable diagnoses } \\
\text { and provide explicit rationales } \\
\text { for management/treatment } \\
\text { options. }\end{array}$} & \multirow{6}{*}{$\begin{array}{l}\text { Provide patients with } \\
\text { comprehensive explanations } \\
\text { about diagnosis and clear } \\
\text { instructions for on-going treatment } \\
\text { or management plans. }\end{array}$} & Dr: & $\begin{array}{l}\text { Now, let me prescribe } \\
\text { you some meds. }\end{array}$ \\
\hline & & $P:$ & Good, good, good. \\
\hline & & Dr: & $\begin{array}{l}\text { Some ointment for you } \\
\text { to apply on that bruised } \\
\text { part, of your arm, huh? }\end{array}$ \\
\hline & & $P:$ & $\begin{array}{l}\text { Mm. Meaning rub it on } \\
\text { and it'll get better? }\end{array}$ \\
\hline & & Dr: & Wait for it to fade, huh. \\
\hline & & $P:$ & Wait for it to fade. \\
\hline
\end{tabular}

2.Researchers refined and utilized a semantic network (Hasan, 1989, 2009; Williams, 1995) to capture and analyze the exchange of meanings in the consultations.

i. The utterance comprising each move was be analyzed into individual messages (a semantic unit closely related to clause at the level of lexico-grammar).

ii. Questions were analyzed using the semantic network segment proposed by Hasan $(1989,2009)$, but it was modified as necessary to meet the descriptive requirements of these data.

iii.Responses were analyzed through the semantic network segment used by Williams (1995), modified as above.

iv.The semantic analyses were examined by native speakers of Cantonese to check on their validity against the original Cantonese utterances, and again modified as necessary.

3.Quantitative data analysis.

In quantitative data analysis, similarities and differences in the discourse patterns across the 10 initial consultations were defined by (a) types of speech functions (e.g., the type of questions raised by the clinicians), the responses by the patients to the various question types; (b) the length of speaking time; (c) the number of turns taken; (d) the number of words spoken; (e) frequencies and the length silence; and (f) the number of back channels, and so on. Figure 3 and 4 provide examples of the different speech functions in Crystal's consultation and Sam's consultation. Figure 5 is the comparison between Crystal and Sam. 
Figure 3. Speech function of Crystal's consultation.

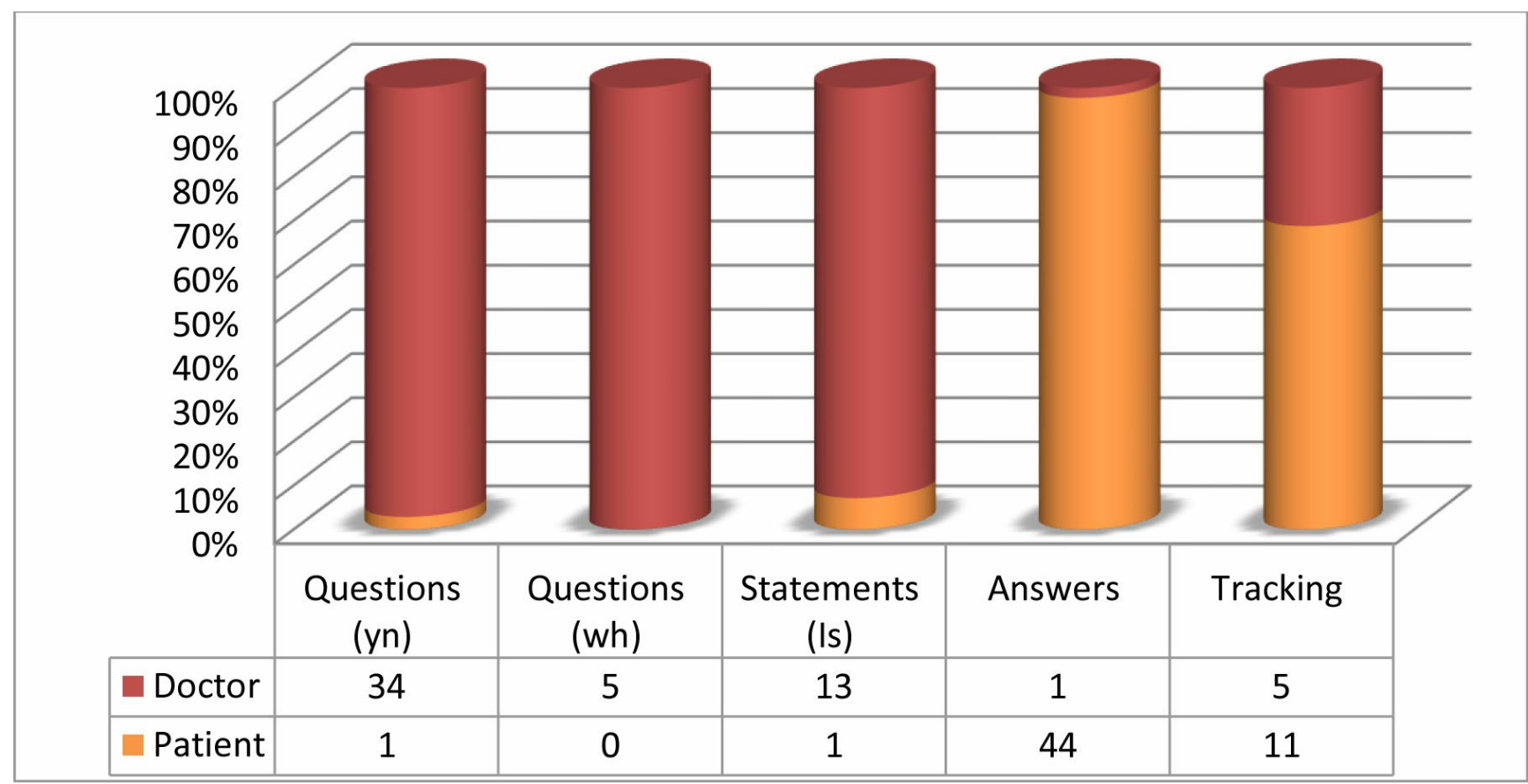

Figure 4. Speech function of Sam's consultation.

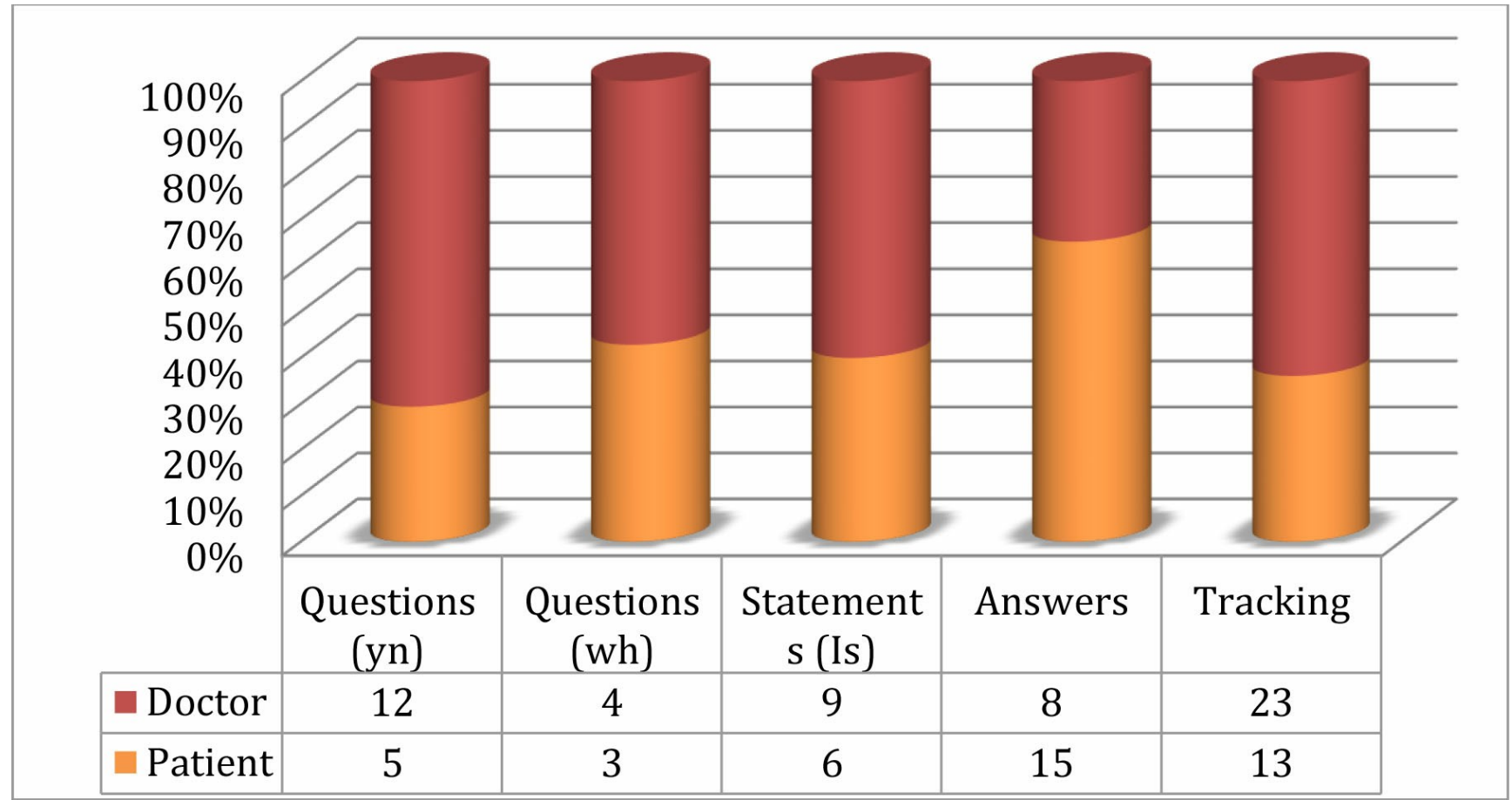


Figure 5. Comparison of speech function between Sam and Crystal in consultation.

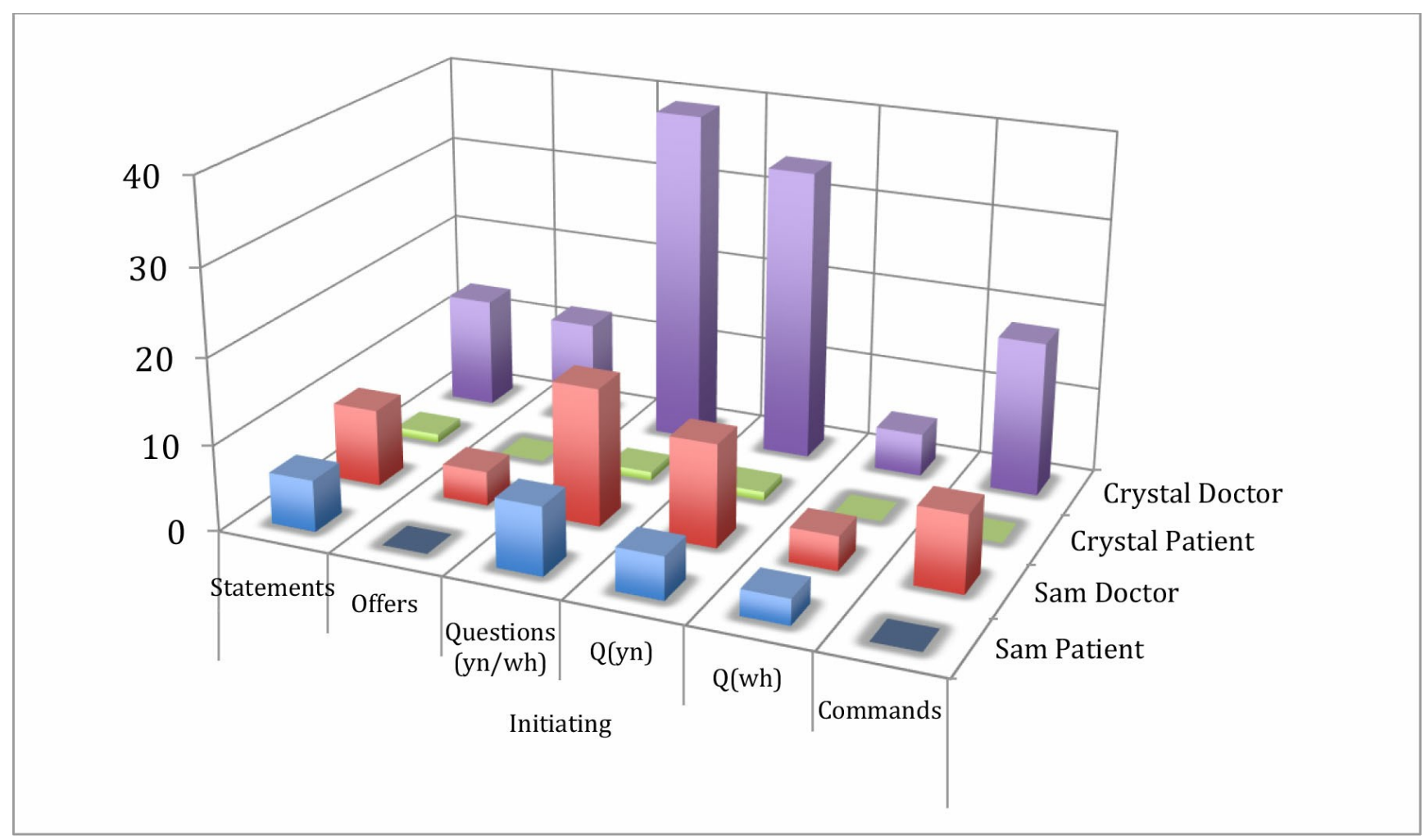

\section{Practical Lessons Learned}

There is clear methodological literature (Candlin \& Candlin, 2003) discussing the strengths and problems of different linguistic approaches to conducting health communication research. It is vital that students read the methodological literature before embarking upon analysis. In addition, the research team would like to summarize the following practical tips, not necessarily found in the traditional methodology textbooks; these points are essential for ethnographic discourse analysis:

\section{Sampling}

A sampling frame should be developed to ensure the balance between the generalizability and validity of the chosen sampling. The sampling frame should consider the representativeness of the selected hospitals or clinical departments. (Clinics in rural areas or community clinics with non-representative populations should be avoided because they might represent heterogeneous patient profiles.)

\section{Factors From the Participants}

Clinicians' educational background, post-training, and years of experiences working in the ED should be taken into account. In addition, patients' socioeconomic backgrounds, their triage 
categories and other medical history (e.g., chronic illness, frequency of ED visits) should be considered when selecting participants for the study.

\section{Consistency of Coding}

After the data are transcribed and translated, the files should be loaded into NVivo software package for coding. First, the doctor and patient's turns are defined, identified by different moves. Based on the analytical framework in the research design described in this study, two independent researchers will code all the transcripts. Then, the coded transcripts will be compared repeatedly, by two researchers, then sorted, recoded and explored for connections among coded segments.

\section{Conclusion}

The ethnographic discourse analysis approach allows researchers to examine the doctorpatient communication in different clinical settings and in multilingual contexts. By analyzing the discourse strategies, grammatical and semantic features of the authentic interactions, researchers can provide an evidence base for the most effective ways in which clinicians can communicate with patients. Ultimately, this research has implications for improving the quality and safety of the patient experience as well as enhancing the professional development of clinicians in high-risk contexts such as EDs.

\section{Note}

1. The semantic analyses were made of data used in developing the report presented in Slade et al 2015, and that further analyses will be made of the remaining data to test the initial findings. For related discussion see Fung, A. (2016). Hasan's semantic networks revisited: a Cantonese systemic functional approach. In W.Bowcher and J.Y.Liang (Eds.), Society in language, language in society. London, England: Palgrave Macmillan.

\section{Exercises and Discussion Questions}

1.What are the advantages and disadvantages of adopting the following research methods and approaches in the flied of applied linguistics when exploring healthcare communication?

a.Grounded theory, quantitative, questionnaire-driven approaches, or the use of quasiexperimental designs involving Likert-scale evaluations of attitude and beliefs.

b.Drawing on discourse analysis, conversational analysis, and interactional sociolinguistics.

c.An analysis of tape-recorded (usually audio-recorded) and transcribed narrative, 
experiential data.

d.Drawn from focus groups, workshops, and individual semi-structured interviews.

e.A synergistic combination of methodologies involving textual analysis, analyses of interaction, ethnographic narratives, and social-historical and structural accounts of the institutions and their associated ideologies that give rise to the data in question.

f. An analysis of the one-on-one interaction between professional and patient, or between researcher and patient

2.What are the most appropriate methods for researching healthcare communication?

3.What value as applied linguistics (or discourse linguists) can we bring to healthcare communication research?

4.How do we make our findings accessible to clinicians and practitioners?

5.What are the challenges for applied linguists when publishing their research in the health science world?

6.Authentic data is prioritized in functional linguistics; why is this? How do we ensure the data is authentic?

\section{Further Reading}

Candlin, C. N., \& Candlin, S. (2003). Health care communication: A problematic site for applied linguistics research. Annual Review of Applied Linguistics, 23, 134-154.

Harvey, K., \& Koteyko, N. (2013). Exploring health communication: Language in action. Oxon, UK: Routledge.

Matthiessen, C. M. I. M. (2013). Applying systemic functional linguistics in healthcare contexts. Text \& Talk, 33, 437-466.

Slade, D., Scheeres, H., Manidis, M., ledema, R., Dunston, R., Stein-Parbury, J., ... McGregor, J. (2008). Emergency communication: The discursive challenges facing emergency clinicians and patients in hospital emergency departments. Discourse \& Communication, 2, 271-298.

Slade, D., Chandler, E., Pun, J., Lam, M., Matthiessen, C. M. I. M., William, G., ... Tang, K. S. (2015). Effective healthcare worker-patient communication in Hong Kong Accident \& Emergency Departments. Hong Kong Journal of Emergency Medicine, 22, 69-83.

\section{Web Resources}

About the International Research Centre for Communication in Healthcare (IRCCH): (http://ircch.org) 
The Centre, co-convened by Hong Kong Polytechnic University (PolyU) and University of Technology, Sydney (UTS), was formally launched at PolyU in June 2013 with over 85 members from over 11 countries. Curtin University, Western Australia, became a strategic partner in July 2013. Since its establishment, the Centre has built on international collaborations formed during the International Roundtable and Symposium on Healthcare Communication hosted by PolyU in 2011. To date, this has led to jointly run colloquia and symposia at different international conferences as well as the formation of new research collaborations. In particular, the development of an International Charter for Human Values in Healthcare has been the result of collaborative effort by people, organizations and institutions around the world working together to restore core human values to healthcare. The values of the International Charter inform the Centre's research, education and practice initiatives.

References

Candlin, C. N., \& Candlin, S. (2003). Health care communication: A problematic site for applied linguistics research. Annual Review of Applied Linguistics, 23, 134-154.

Chandler, E., Slade, D., Pun, J., Lock, G., Matthiessen, C. M. I. M., Espindola, E., \& Ng, C. (2015). Communication in Hong Kong Accident \& Emergency Departments: The clinicians' perspectives. Global Qualitative Nursing Journal, 2, 1-11. doi:http://dx.doi.org/10.1177/2333393615576714

Chiesa, M., \& Hobbs, S. (2008). Making sense of social research: How useful is the Hawthorne effect? European Journal of Social Psychology, 38, 67-74. doi:http://dx.doi.org/10.1002/ejsp.40

Eggins, S., \& Slade, D. (1997). Analysing casual conversation. London, England: Cassell.

Halliday, M. A. K. (1973). Explorations in the functions of language. London, England: Edward Arnold.

Hasan, R. (1983). A semantic network for the analysis of messages in everyday talk between mothers and their children (Mimeo). Department of Linguistics, Macquarie University, Sydney, NSW, Australia.

Hasan, R. (1989). Semantic variation and sociolinguistics. Australian Journal of Linguistics, 9, 221-275.

Hasan, R. (1996). Ways of saying: Ways of meaning: Selected papers of Ruqaiya Hasan (C. Cloran, D. Butt, and G. Williams, Ed.). London, England: Cassell.

Hasan, R. (2009). Semantic variation: Meaning in society and in sociolinguistics (J. J. Webster, Ed.). London, England: Equinox. 
Izawa, M. R., French, M. D., \& Hedge, A. (2012). Shining new light on the Hawthorne illumination experiments. Human Factors,

53 , 528-547. doi:http://dx.doi.org/10.1177/0018720811417968

Rider, E. A., Kurtz, S., Slade, D., Longmaid, H. E., III, Ho, M. J., Pun, K. H. J., ... Branch, W. T. (2014). The International Charter for Human Values in Healthcare: An interprofessional global collaboration to enhance values and communication in healthcare. Patient Education and Counselling, 96, 273-280. doi:http://dx.doi.org/10.1016/j.pec.2014.06.017

Robson, C. (2002). Real world research: A resource for social scientists and practitionerresearchers. Oxford, UK: Blackwell.

Sedwick, P. (2012). The Hawthorne effect. British Medical Journal, 344, d8262. doi:http://dx.doi.org/10.1136/bmj.d8262

Slade, D. (1997). The texture of casual conversation: A multidimensional interpretation (PhD thesis). Linguistics Department, University of Sydney, Sydney, Australia.

Slade, D., Chandler, E., Pun, J., Lam, M., Matthiessen, C. M. I. M., William, G., ... Tang, K. S. (2015). Effective Healthcare worker-patient communication in Hong Kong Accident \& Emergency Departments. Hong Kong Journal of Emergency Medicine, 22, 69-83.

Slade, D., Manidis, M., McGregor, J., Scheeres, H., Stein-Parbury, J., Dunston, R., ... Herke, M. (2011). Communicating in hospital emergency departments: Final report. Sydney, Australia: University of Technology.

Slade, D., Matthiessen, C. M. I. M., Lock, G., Pun, J., \& Lam, M. (2016). The interplay of interpersonal and experiential meanings in doctor-patient communication and its impact on health outcomes in a Hong Kong Accident and Emergency Department. In L. Ortega, A. Tyler, \& H. I. Park (Eds.), The usage-based study of language learning and multilingualism (pp. 235254). Washington, DC: Georgetown University Press.

Williams, G. (1995). Joint book-reading and literacy pedagogy: A socio-semantic examination (PhD dissertation). Department of Linguistics, Macquarie University, Sydney, NSW, Australia.

Williams, G. (2001). Literacy pedagogy prior to schooling: Relations between social positioning and semantic variation. In A. Morais, I. Neves, B. Davies, \& H. Baillie (Eds.), Towards a sociology of pedagogy: The contribution of Basil Bernstein to research (pp. 17-45). New York, NY: Peter Lang. 